\title{
REVIEW
}

\section{The 2015 Dutch food-based dietary guidelines}

\author{
D Kromhout, CJK Spaaij, J de Goede and RM Weggemans for the Committee Dutch Dietary Guidelines $2015^{1}$
}

The objective of this study was to derive food-based dietary guidelines for the Dutch population. The dietary guidelines are based on 29 systematic reviews of English language meta-analyses in PubMed summarizing randomized controlled trials and prospective cohort studies on nutrients, foods and food patterns and the risk of 10 major chronic diseases: coronary heart disease, stroke, heart failure, diabetes, breast cancer, colorectal cancer, lung cancer, chronic obstructive pulmonary disease, dementia and depression. The committee also selected three causal risk factors for cardiovascular diseases or diabetes: systolic blood pressure, low-density lipoprotein cholesterol and body weight. Findings were categorized as strong or weak evidence, inconsistent effects, too little evidence or effect unlikely for experimental and observational data separately. Next, the committee selected only findings with a strong level of evidence for deriving the guidelines. Convincing evidence was based on strong evidence from the experimental data either or not in combination with strong evidence from prospective cohort studies. Plausible evidence was based on strong evidence from prospective cohort studies only. A general guideline to eat a more plant food-based dietary pattern and limit consumption of animal-based food and 15 specific guidelines have been formulated. There are 10 new guidelines on legumes, nuts, meat, dairy produce, cereal products, fats and oils, tea, coffee and sugar-containing beverages. Three guidelines on vegetables, fruits, fish and alcoholic beverages have been sharpened, and the 2006 guideline on salt stayed the same. A separate guideline has been formulated on nutrient supplements. Completely food-based dietary guidelines can be derived in a systematic and transparent way.

European Journal of Clinical Nutrition (2016) 70, 869-878; doi:10.1038/ejcn.2016.52; published online 6 April 2016

\section{INTRODUCTION}

Dietary guidelines are evidence-based integrated messages to reduce the risk of chronic diseases for the general population. They summarize and synthesize knowledge regarding nutrients and foods. The first dietary guidelines for the Dutch population appeared in 1986 and comprised five nutrient-based guidelines. ${ }^{1}$ The guidelines were updated in 2006 and consisted of four nutrient-based and four food-based guidelines. ${ }^{2}$

Nutrient metrics for the prevention of chronic diseases have major limitations; for example, total protein, fat and carbohydrate intake are not related to chronic diseases, and individual nutrients, for example, fatty acids and sodium, have limited effects. Increasing evidence from controlled trials on risk factors and prospective cohort studies shows that specific foods and dietary patterns substantially affect chronic disease risk. ${ }^{3}$ Therefore, the 2015 Dutch dietary guidelines are completely food-based.

\section{MATERIALS AND METHODS}

A multidisciplinary committee of 15 scientists was appointed, who filled out a declaration of interest published on the website of the Health Council (www.gr.nl). First, a methodology document was prepared. ${ }^{4}$ The committee evaluated the peer-reviewed literature on the relationships among nutrients, foods, food patterns and the risk of the 10 major diet-related chronic diseases based on mortality, life-years lost and burden of disease in The Netherlands. The diseases are as follows: coronary heart disease (CHD), stroke, heart failure, type 2 diabetes, chronic obstructive pulmonary disease, breast cancer, colorectal cancer, lung cancer, dementia and depression. The committee selected also three risk factorssystolic blood pressure, low-density lipoprotein (LDL)-cholesterol and body weight-that are causally related to at least one of the following chronic diseases: CHD, stroke, heart failure and type 2 diabetes. ${ }^{4}$ These risk factors are not causally related to the other six chronic diseases.

The committee selected prospective cohort studies in which the diet was assessed before the disease was diagnosed, because food intake data are more reliable when estimated before disease occurs. The guidelines are also based on randomized controlled trials (RCTs). Both types of prospective studies have advantages but also disadvantages. ${ }^{5}$ RCTs have the advantage of exclusion of confounding and provide strong evidence for causality but generally include selected populations with short follow-up periods. Prospective cohort studies are generally characterized by large populations and long follow-up periods but can never rule out residual confounding.

The committee limited the literature search to studies on adults and children from the age of 2 years onwards and did not include studies on pregnant or lactating women. The literature search of the committee was primarily restricted to pooled analyses, metaanalyses and systematic reviews published in peer-reviewed journals. Literature searches for the background documents covered publications up to July 2014 in PubMed. The committee only included the results of pooled analyses or meta-analyses published thereafter if they either were the first one or reported deviant conclusions from previous meta-analyses.

\footnotetext{
The Health Council of the Netherlands, The Hague, The Netherlands. Correspondence: Dr RM Weggemans, The Health Council of the Netherlands, PO Box 16052,2500 BB The Hague, The Netherlands. 
The committee evaluated the state-of-the-art of science on nutrition and chronic diseases described in 29 background documents. The formulation of the guidelines is only based on conclusions with strong evidence, but it differs for RCTs and cohorts studies. The committee used the word 'effect' for RCTs on dietary factors and causal risk factors or chronic disease incidence and 'association' for cohort studies of dietary factors and chronic disease incidence. The level of evidence depended on the availability and quality of the research, the strength of the associations and the presence of heterogeneity in meta-analysis. Finally, the health council provided the opportunity to comment on drafts of the background documents by public consultation. Comments of stakeholders and responses of the committee have been published on the website of the Council (www.gr.nl) in Dutch.

For the integration of the results into guidelines, foods and nutrients were classified with the food education message to the consumer in mind. The committee composed the following groups: vegetables and fruit, protein-rich foods, carbohydrate and fibre-rich foods, fat-rich foods and fish, beverages, salt, food patterns and nutrient supplements. Next, the committee described for each food and the associated nutrient(s) the results from RCTs and/or cohort studies with strong evidence. The conclusion(s) on which the guidelines were based are described in Supplementary Tables 1-17 in Supplementary Appendix 2. If available, information on associations of the dietary factor with other chronic diseases is also described. In the tables, the quantitative results are specified as comparisons between high and low intake levels or in terms of dose-response relations. The relative risks are rounded off to 5 or $10 \%$ in order to avoid seeming accuracy.

Judgements were made on the totality of evidence of the selected findings. If the results of cohort studies on chronic diseases and at least one individual RCT with disease as end point were consistent, the committee regarded the evidence as convincing. The committee called the evidence also convincing if the results of the cohort studies and RCTs with a causal risk factor were consistent. Finally, a significant effect on a causal risk factor was also called convincing. If only results of cohort studies were available, the committee judged the association plausible. Only in the case of convincing evidence from both cohort studies and RCTs the guideline is quantified by means of the consumption levels observed in cohort studies. Consumption levels are much higher in RCTs because their objective is to show a causal relation. If the evidence concerns the replacement of a food by another one, the guideline is formulated in terms of replacement.

\section{RESULTS}

Most data relate to effects observed in adults, whereas data on children aged 2 years and older are scarce.The committee provides guidelines for five food groups, two groups of beverages and one group of food patterns. In addition, guidelines on salt and nutrient supplements are derived. First, the conclusions from the background documents are described that are relevant for the guideline. Thereafter, the committee formulates the guideline.

Vegetables and fruit

Vegetables and fruit are defined based on their nutritional value, taste and culinary application of plant foods. Although cucumber, tomatoes and red pepper are fruits in the botanical classification, they are classified as vegetables. In addition, green peas, sugar peas, broad beans and butter beans are classified as vegetables. Vegetable juices are not included in the definition of vegetables. In the different studies, fruit includes fresh fruit but also dried and canned fruit and sometimes fruit juice. ${ }^{6}$ In addition, the results of fruit fibre are evaluated including pectin.
The committee concludes that the consumption of vegetables and fruit convincingly reduces the risk of $\mathrm{CHD}$ and stroke because the results from RCTs and cohort studies support each other. Vegetables and fruit reduced blood pressure $^{7-12}$ and were associated with a lower risk of $\mathrm{CHD}^{13-15}$ and stroke. ${ }^{16}$ The effect of pectin in fruit on LDL-cholesterol also supported the causal relation of fruit consumption with CHD risk. ${ }^{17}$ Green leafy vegetables and fruit were also associated with lower diabetes risk, $^{6,18}$ vegetables and fruits with lower colorectal cancer risk. ${ }^{19}$ Fruit consumption was associated with a lower risk of lung cancer. $^{20-22}$ Main conclusions supporting the guideline on vegetables and fruit are shown in Supplementary Table 1 in Supplementary Appendix 2.

Guideline. Eat at least $200 \mathrm{~g}$ of vegetables and at least $200 \mathrm{~g}$ of fruit daily.

\section{Protein-rich products}

Meat. The major types of meat discriminated in the studies are red, processed and white meat. Red meat is derived from mammals such as cows, calves, pigs, goats, sheep and horses. Processed meat is smoked or salted for conservation purposes or when preservatives such as nitrate or nitrite are added. Processed meat comprises cured meat products such as ham, bacon, sausages and ready-to-eat minced meat. White meat is derived from chickens, turkeys, ducks, geese and domesticated rabbits. ${ }^{23}$

The committee concludes that it is plausible that the consumption of red meat and processed meat is associated with a higher risk of stroke, ${ }^{24,25}$ diabetes, $^{26-29}$ colorectal $^{30-35}$ and lung cancer $^{36,37}$ (Supplementary Table 2 in Supplementary Appendix 2). The associations were stronger for processed meat than for red meat. There is insufficient evidence for associations of white meat with chronic diseases. ${ }^{29,32,35,36,38,39}$

Guideline. Limit the consumption of red meat, particularly processed meat.

Dairy. Dairy includes, among others milk, yogurt and cheese. Butter is excluded from the definition of dairy, as it is included in the food group fats and oils.

The committee concludes that it is plausible that the consumption of dairy and milk is associated with a lower risk of colorectal cancer ${ }^{40,41}$ and the consumption of yogurt with a lower risk of diabetes ${ }^{42}$ (Supplementary Table 3 in Supplementary Appendix 2). The conclusion about colorectal cancer is supported by the finding that the intake of calcium from supplements was associated with a lower risk of this disease. ${ }^{31,43,44}$ The calcium intake from supplements was approximately about half the amount from dairy. ${ }^{45} \mathrm{~A}$ distinction between the effects of lowfat and high-fat dairy produce was not possible, because of insufficient evidence.

Guideline. Take a few portions of dairy produce daily, including milk or yogurt.

Eggs. Eggs are not only a source of protein but also a source of dietary cholesterol ( $200 \mathrm{mg}$ of cholesterol per egg). In the Dutch food pattern, other important sources of cholesterol are meat and milk products. ${ }^{45}$ In 2006, the Health Council decided not to formulate a guideline for eggs or dietary cholesterol, ${ }^{2}$ and the present committee concludes that more recent evidence does not warrant changing this. The available evidence shows that the intake of $100 \mathrm{mg}$ of cholesterol from eggs increased LDLcholesterol by $0.05 \mathrm{mmol} / \mathrm{l} .{ }^{46,47}$ These results are from controlled experiments in which the consumption of eggs was considerably larger than habitual. In cohort studies, there is no association between eggs and CHD risk. ${ }^{48,49}$ It is plausible that the 
consumption of seven eggs per week and a high intake of dietary cholesterol are associated with a higher risk of diabetes. ${ }^{49}$ However, the intake of cholesterol-rich foods is still unaltered and low in the Dutch population. ${ }^{45}$ The 2006 guidelines stated that a more than average consumption of cholesterol-rich foods is not desirable. ${ }^{2}$ The committee subscribes this and recommends monitoring the consumption.

Legumes. Legumes are defined as (soya) beans, lentils, chick peas and split peas. Green peas, sugar peas, broad beans and butter beans belong to the green vegetables and are reviewed together with vegetables and fruit. Most studies included peanuts as nuts.

The committee concludes that the consumption of legumes convincingly reduces LDL-cholesterol ${ }^{50,51}$ (Supplementary Table 4 in Supplementary Appendix 2), a causal risk factor of CHD. However, there are insufficient data from cohort studies on the association between legumes and $\mathrm{CHD}^{52}$ to quantify the guideline.

\section{Guideline. Eat legumes weekly.}

Nuts. The committee defines nuts similarly to most researchers and consumers, and it does not use the botanical classification. Among the most frequently consumed ones are walnuts, almonds, hazel nuts, cashew nuts, pistachios, macadamia nuts, Brazil nuts and pecans. Peanuts are also included.

The committee concludes that the consumption of nuts convincingly reduces CHD risk (Supplementary Table 5 in Supplementary Appendix 2). Consumption of nuts reduced LDLcholesterol in RCTs ${ }^{53-55}$ and was associated with a lower risk of CHD in cohort studies. ${ }^{52,56}$ In addition, the PREDIMED-RCT showed that the consumption of 30 grams of nuts per day reduced the incidence of cardiovascular diseases in high-risk patients. ${ }^{57}$

Guideline. Eat at least $15 \mathrm{~g}$ of unsalted nuts daily.

\section{Carbohydrate- and fibre-rich products}

Cereals consist, among others, of wheat, rice, oats, rye and barley. Examples of cereal products are bread, cereals, crackers, flour, pasta and so on. In The Netherlands, whole-grain bread must consist of $100 \%$ whole-grain flour, but the qualification of wholegrain is not protected for other products. In research on diet and chronic diseases, products are frequently called whole-grain if they consist for at least $25 \%$ of whole-grain flour. ${ }^{58-61}$ Potatoes are also a source of starch and fibre. However, there is a lack of scientific information on their health effects. Dietary fibre is a collection of compounds with various physiological functions. The fibre intake in cohort studies concerns fibres of natural sourcesfor example, wholemeal bread, legumes, potatoes, vegetables and fruit. $\beta$-Glucan is a type of fibre in oats and barley.

The committee concludes that the consumption of whole-grain products convincingly reduces the risk of CHD and dietary fibre reduces the risk of stroke (Supplementary Table 6 in Supplementary Appendix 2). The results of RCTs and cohort studies on whole-grain products and fibre are consistent. Dietary fibre reduced diastolic blood pressure in $\mathrm{RCTs}^{62,63}$ and the risk of $\mathrm{CHD}^{64}$ and stroke ${ }^{65,66}$ in cohort studies. In addition, RCTs showed that oats ${ }^{67}$ and $\beta$-glucan ${ }^{17,68-70}$ reduced LDL-cholesterol. In cohort studies, a high intake of cereal fibre ${ }^{64}$ and whole-grain products $^{71-74}$ was associated with a lower risk of CHD. A high intake of dietary and cereal fibre and whole-grain products was also related to a lower risk of diabetes ${ }^{75-77}$ and colorectal cancer. $^{78-81}$

Guidelines. Eat at least $90 \mathrm{~g}$ of brown bread, wholemeal bread or other whole-grain products daily. Replace refined cereal products by whole-grain products.
Fat-rich products and fish

Fats and oils. Fat-rich products - for example, butter, margarine and oil-contain a combination of various fatty acids. Until the 1990s, the Dutch diet contained a large amount of trans-fatty acids, but nowadays the intake is below $1 \%$ of energy. This major change was brought about after it became clear that trans-fatty acids increase the risk of CHD. Trans-fatty acids are still present in bakery, meat and dairy products. Butter contains more saturated fatty acids than soft margarines and liquid oils. Olive oil contains mostly cis-monounsaturated fatty acids. Sunflower oil contains a lot of cis-unsaturated fatty acids, of which two-thirds are polyunsaturated fatty acids. Vegetable fats and oils contain generally a small amount of saturated and a large amount of unsaturated fatty acids. Exceptions are palm oil, coconut fat and cocoa butter, which contain a lot of saturated fatty acids.

The committee concludes that foods rich in cis-unsaturated fatty acids, such as soft margarines or vegetable oils, convincingly reduce the risk of $\mathrm{CHD}$ compared with foods rich in saturated fatty acids such as butter and hard margarines (Supplementary Table 7 in Supplementary Appendix 2). The results of the RCTs showed a reduction in LDL-cholesterol when butter was replaced by soft margarine ${ }^{82}$ and when saturated fatty acids was replaced by unsaturated fatty acids. ${ }^{83}$ Replacement of saturated fatty acids by polyunsaturated fatty acids reduced the risk of CHD. ${ }^{84-88}$ This is confirmed in cohort studies. ${ }^{89}$ The PREDIMED-RCT showed that $50 \mathrm{ml}$ of olive oil per day reduced the risk of cardiovascular diseases in high-risk patients. ${ }^{57}$

Trans-fatty acids increase the risk of CHD convincingly. RCTs showed that replacement of $1 \%$ of energy from trans-fatty acids with unsaturated fatty acids reduced LDL-cholesterol by $0.04 \mathrm{mmol} / \mathrm{l} .{ }^{83,90}$ Trans-fatty acid intake was associated with a higher risk of CHD in cohort studies. ${ }^{88,91}$

The current intake of trans-fatty acids is below $1 \%$ of energy. ${ }^{45}$ The Committee concludes that for such a low level of trans-fatty acids a guideline is not needed, but monitoring of the intake is required because of the negative health effects of a higher intake of trans-fatty acids.

Guideline. Replace butter, hard margarines and cooking fats with soft margarines, liquid cooking fats and vegetable oils.

Fish and fish fatty acids. Fish is an important source of the very long-chain polyunsaturated fatty acids eicosapentaenoic acid and docosahexaenoic acid and essential nutrients such as vitamin D, iodine and selenium. Examples of oily fish are herring, salmon and mackerel, and examples of lean fish are cod, plaice and coal-fish.

The committee concludes that eating fish convincingly reduces the risk of fatal CHD (Supplementary Table 8 in Supplementary Appendix 2). The fish fatty acids eicosapentaenoic acid and docosahexaenoic acid reduced in RCTs the risk of fatal CHD in cardiac patients and high-risk groups, ${ }^{92-97}$ and the consumption of one serving of fish per week was associated with a lower risk of fatal CHD in cohort studies. ${ }^{98,99}$ In addition, one RCT showed that two servings of oily fish per week reduced the risk of fatal CHD in cardiac patients. ${ }^{100}$ In addition, cohort studies showed that the consumption of one serving per week was associated with a lower risk of stroke. ${ }^{101-103}$ At a consumption level of one serving per week, there is no evidence for toxicological risks if a variety of different types of fish are eaten. ${ }^{104}$

Guideline. Eat one serving of fish, preferably oily fish weekly.

\section{Beverages}

Tea. Tea is defined as black and green tea. Green tea is derived from the tea plant but the leaves have not undergone an oxidation process in contrast to black tea. Herb teas and, for example, rooibos tea were not reviewed. 
The committee concludes that the consumption of tea convincingly reduces the risk of stroke (Supplementary Table 9 in Supplementary Appendix 2). RCTs showed that three cups of green tea ${ }^{105,106}$ and five cups of black tea ${ }^{107}$ reduced blood pressure, and cohort studies showed that the consumption of tea was associated with a lower risk of stroke. ${ }^{108}$ The consumption of black tea and green tea was also associated with a lower risk of diabetes. $^{109}$

\section{Guideline. Drink three cups of tea daily.}

Coffee. For coffee, it is relevant to know in which way it is prepared-with a filter or not-because the filter can take away the cholesterol-elevating compounds kahweol and cafestol. ${ }^{110}$ Coffee pads, dissolved coffee and machine coffee based on liquid coffee concentrate are examples of filtered coffee. Examples of unfiltered coffee are boiled coffee, caffetiere coffee, Greek coffee and Turkish coffee. Espresso and some types of machine coffee can be filtered or unfiltered depending on the machine, type and amount of coffee and the type of filter used. ${ }^{111}$

The committee concludes that in RCTs unfiltered coffee convincingly increases LDL-cholesterol ${ }^{112}$ (Supplementary Table 10 in Supplementary Appendix 2), a causal risk factor of CHD. Coffee was associated with a lower risk of CHD, stroke and diabetes in recently carried out cohort studies. ${ }^{113}$ These studies concern mostly filtered coffee.

Guideline. Replace unfiltered coffee by filtered coffee.

Sugar-containing beverages. Sugar-containing beverages such as drinks with added sugar and fruit juice have similar sugar content. Beverages with added sugar are cold drinks with extra sucrose, fructose or glucose. Examples of sugar-containing beverages are fruit juice, soda, ice tea, vitaminated water, sport beverages and sweetened dairy drinks.

The committee concludes that the consumption of beverages with added sugar convincingly increases the risk of diabetes (Supplementary Table 11 in Supplementary Appendix 2). RCTs showed that these beverages increased body weight, ${ }^{114}$ and cohort studies pointed to an association with diabetes. ${ }^{115,116}$ These results can also be applied to other beverages such as fruit juice and sweetened dairy drinks. Good alternatives for sugarcontaining beverages are tea and filtered coffee without sugar and water.

Guideline. Minimize the consumption of sugar-containing beverages.

\section{Alcoholic beverages}

In The Netherlands, a standard glass of alcoholic beverages amounts to $\sim 10 \mathrm{~g}$ of alcohol, equivalent to $13 \mathrm{ml}$ of alcohol. That amount of alcohol is present in $250 \mathrm{ml}$ of beer (5\% alcohol), $100 \mathrm{ml}$ of wine (12\% alcohol) and $35 \mathrm{ml}$ of spirits (35\% alcohol).

The committee concludes that a high intake of alcohol convincingly increases the risk of stroke and that binge drinking (60 $\mathrm{g}$ or more at one occasion) increases the risk of CHD (see Supplementary Table 12 in Supplementary Appendix 2). RCTs showed that decreasing a high level of alcohol intake reduced blood pressure. ${ }^{117}$ Cohort studies showed that a high $(30-60 \mathrm{~g}$ per day) compared with a moderate intake of alcohol (1-15 g per day) was associated with a higher risk of stroke, ${ }^{118}$ and binge drinking was associated with a higher risk of CHD. ${ }^{119}$ In addition, a high intake of alcohol was associated with a higher risk of breast cancer ${ }^{120-122}$ and colorectal cancer, ${ }^{123-125}$ and a high consumption of beer and spirits was associated with a higher risk of lung cancer. ${ }^{126,127}$
Low levels of alcohol intake ( $<15 \mathrm{~g}$ per day) were associated with a lower risk of cardiovascular diseases, ${ }^{118,128}$ diabetes ${ }^{129-131}$ and dementia ${ }^{132}$ and with a higher risk of breast cancer ${ }^{120-122}$ as compared with (almost) no alcohol intake. A low level of beer among men and a low level of spirits among women were associated with a higher risk of diabetes, ${ }^{130}$ and a low level of beer and wine was associated with a lower risk of lung cancer. ${ }^{126,127}$ The associations of low alcohol intake with the risk of chronic disease are shown in Supplementary Table 13 and with the risk of all-cause mortality in Supplementary Table 14 in Supplementary Appendix 2.

A low level of beer consumption was associated with a higher risk of all-cause mortality. ${ }^{133} \mathrm{~A}$ low level of wine consumption was associated with a lower risk of all-cause mortality. ${ }^{133}$ One glass of alcohol every two days was associated with a lower risk of allcause mortality. ${ }^{133,134}$

Guideline. Do not drink alcohol or do not drink more than one glass daily.

Salt

Salt (sodium chloride) is present in many foods and is added to foods. Of the total salt content of the diet, $\sim 20 \%$ is added in the kitchen or at the table and about $80 \%$ in foods as purchased. Foods often containing much salt are bread, cheese, sausages, hearty snacks and ready-to-eat products. One gram of sodium is equivalent to $\sim 2.5 \mathrm{~g}$ of salt.

The committee concludes that, in a large number of RCTs, lowering sodium intake reduces blood pressure ${ }^{135-137}$ (see Supplementary Table 15 in Supplementary Appendix 2), a causal risk factor of cardiovascular diseases. The protective effect of a low intake of sodium was stronger in people with hypertension than in those with normotension. ${ }^{135-137}$ The guideline could not be quantified because of insufficient data from high-quality cohort studies on sodium intake and cardiovascular risk. Therefore, the committee decided to stay with the 2006 Dutch guideline that recommended limiting the intake of salt to $6 \mathrm{~g}$ per day.

Guideline. Limit salt intake to $6 \mathrm{~g}$ daily.

\section{Nutrient supplements}

Nutrient supplements are vitamins and/or minerals that are taken in addition to the usually consumed diet. These supplements are available in the form of powders, pills, drops and effervescent tablets. In RCTs, the supplements are generally taken in high dosages that cannot be obtained from the usual diet. ${ }^{138}$

The committee concludes that in RCTs $\beta$-carotene supplements convincingly increase the risk of lung cancer in smokers and asbestos workers. ${ }^{139,140}$ Supplements with vitamin D and calcium convincingly reduce the risk of fractures in the elderly and postmenopausal women. ${ }^{141}$ These effects are shown in Supplementary Table 17 in Supplementary Appendix 2. The committee also concludes that there is insufficient evidence for an effect of vitamin C supplements on cardiovascular risk. Supplementation with vitamin $C$ reduced blood pressure, ${ }^{142}$ but one RCT showed that the effect of $500 \mathrm{mg}$ of vitamin $C$ per day did not affect cardiovascular risk. ${ }^{143}$

Guideline. Nutrient supplements are not needed, except for specific groups for which supplementation applies- for example, groups that need extra vitamin D, folic acid or vitamin B12.

\section{Dietary patterns}

Dietary patterns are defined on the basis of the amounts, ratios, variation and the combination of different foods and beverages and the frequency in which they are used. ${ }^{144}$ There are many 
food-based recommended dietary patterns. Examples are the traditional Mediterranean diet, the new Nordic diet and the American Dietary Approaches to Stop Hypertension diet. These patterns are characterized by basic foods that may differ in quantities. They score high on vegetables, fruit, whole-grain products, nuts, legumes, oils rich in cis-unsaturated fatty acids, low-fat dairy, poultry and fish, and score low on red and processed meat, high-fat dairy, hard fats, salt, sugar-sweetened beverages and moderate on alcohol. The patterns are characterised by more plant foods and less animal foods. Vegetarian patterns are characterised by the absence of meat and sometimes also other animal products.

The committee concludes that recommended dietary patterns convincingly reduce the risk of CHD and stroke (see Supplementary Table 17 in Supplementary Appendix 2). RCTs showed that such dietary patterns reduced blood pressure ${ }^{145-148}$ and cohort studies were associated with a lower risk of CHD and stroke. $^{144,149,150}$ RCTs also showed that vegetarian patterns reduced blood pressure ${ }^{151}$ and that cohort studies were associated with a lower risk of CHD. ${ }^{152,153}$ The different recommended dietary patterns were also associated with a lower risk of diabetes, ${ }^{154-156}$ colorectal cancer ${ }^{157}$ and death from all causes $^{158}$ in cohort studies. In high-risk patients, the PREDIMEDRCT showed a protective effect on cardiovascular risk of a Mediterranean-style diet with extra-virgin olive oil ( $50 \mathrm{ml}$ per day) or an additional amount of nuts ( $30 \mathrm{~g}$ per day) compared with a pattern with less fat. ${ }^{57}$

Guideline. Follow a dietary pattern that involves eating more plant-based and less animal-based food, as recommended in the guidelines.

\section{DISCUSSION}

The guidelines provide information about which foods and dietary patterns result in health gain based on state-of-the-art science. The committee judged the underpinning of most guidelines as 'convincing'; only the underpinning of the guidelines on meat and dairy is 'plausible'.

The average Dutch consumption pattern already meets the guideline on dairy, but with the other guidelines substantial health gain can be obtained. ${ }^{45}$ However, the maximum health gain of all guidelines together cannot be quantified. Most relative risks in the tables are in the order of magnitude of $10-20 \%$ and are small. Because of the correlations among food groups, the effects are not additive. However, the results of the PREDIMED-RCT suggest that the more the guidelines are adhered to, the greater the health gain compared with the findings of the cohort studies on dietary patterns. ${ }^{57}$

The guidelines propagate a shift into the direction of plant foods. It has convincingly been shown that this will result in health gain at the population level. An example is the doubling of the vegetable and fruit consumption compared with the average current consumption. In addition, replacement of refined cereal products with wholemeal bread or other whole-grain products has positive health effects. Health gain can also be obtained by eating more legumes and nuts. Only $10 \%$ of the Dutch population already eat small amounts of these products; about half of the population does not eat legumes and nuts or eats only very little.

The consumption of animal products also needs adjustment. Although the scientific data are not as solid as those for plant products, it is plausible that moderation of meat consumption is good for health. The consumption of both processed meat and red meat (especially for men) is on a level that is associated with a higher risk of chronic diseases. In contrast, it is favourable to eat more fish. As only half of the Dutch population eats fish twice or three times a month, an increase to one serving a week is beneficial for health.
In addition, a shift in the consumption of beverages is desirable. Health gain is obtained if sugar-containing beverages in children (average Dutch consumption three quarters of a litre per day) and adults (a quarter to a third litre) are replaced by water or by tea and filtered coffee without sugar. People who drink alcohol should limit the amount to one glass per day and avoid binge drinking.

Health gain can also be expected from limiting salt intake. This can be realized by avoiding processed foods and by not adding salt during cooking or at the table. Furthermore, it is favourable to replace butter, hard margarines, cooking fats by soft margarines, liquid cooking fats and vegetable oils. For special population groups, it is important to use extra vitamin D. In addition, women with the desire to become pregnant have to take extra folic acid, and vegans need extra vitamin B12. For the general population, it is not needed to take nutrient supplements for the prevention of chronic diseases.

Not all diet-related disorders were reviewed for the guidelines such as constipation and dental caries. Still the guidelines promote the prevention of these disorders: a higher intake of fibre prevents constipation and less (frequent) sugar consumption helps to prevent caries. ${ }^{2,159}$

The guidelines are intended for use in the prevention of chronic diseases in the general population. Pregnant women, newborns and children up to 2 years old are outside the scope of the guidelines. Most research data relate to effects observed in adults. Although the committee included studies in children aged two and older, the data available for this group are scarce.

General

- Follow a dietary pattern that involves eating more plant-based food and less animal-based food, as recommended in the guidelines.

\section{Higher consumption recommended}

- Eat at least $200 \mathrm{~g}$ of vegetables and at least $200 \mathrm{~g}$ of fruit daily.

- Eat at least $90 \mathrm{~g}$ brown bread, wholemeal bread or other wholegrain products daily.

- Eat legumes weekly.

- Eat at least $15 \mathrm{~g}$ of unsalted nuts daily.

- Eat one serving of fish, preferably oily fish, weekly.

- Drink three cups of tea daily.

\section{Replacement recommended}

- Replace refined cereal products by whole-grain products.

- Replace butter, hard margarines and cooking fats by soft margarines, liquid cooking fats and vegetable oils.

- Replace unfiltered coffee by filtered coffee.

\section{Limitation recommended}

- Limit the consumption of red meat, particularly processed meat.

- Minimize the consumption of sugar-containing beverages.

- Do not drink alcohol or no more than one glass daily.

- Limit salt intake to $6 \mathrm{~g}$ daily.

- Nutrient supplements are not needed, except for people who belong to a group for which supplementation applies.

\section{Maintenance of current consumption recommended}

- Take a few portions of dairy produce daily, including milk or yogurt.

In 2011, the Health Council published an advice in which the Dietary guidelines were reviewed on ecological aspects. ${ }^{160}$ Recently, the findings in this advice were confirmed in various 
peer-reviewed articles. ${ }^{161-164}$ The Committee compared the findings in that advice with those of the current guidelines and concluded that complying to a number of guidelines will not only result in health gain but also in a lower ecological burden. Limiting meat consumption is also desirable from an ecological perspective. Generally, a more plant-food- and less animal-food-based dietary pattern is associated with a lower ecological burden. It means that for a high dairy consumption moderation is also advisable. This also holds for fish: compared with the 2006 guideline (two servings of fish a week), the current guideline to eat fish once a week results in a lower ecological burden. For fish consumption, it is recommended to emphasize that the types of fish that are not overfished or are cultivated in an environmentfriendly manner are eaten. From an ecological perspective, it is not enough to adhere to the guidelines. To limit the foodrelated ecological burden, also measures are needed in the production lines. ${ }^{165}$

The guidelines deal primarily with nutrition behaviour of the consumer. In addition, other parties have instruments to favourably influence behaviour and to make the healthy choice the easy choice. The earlier edition of the guidelines and the advice of the Health Council on food logos pointed also into this direction (www.gr.nl). ${ }^{2,166}$ The food industry has possibilities to promote product development and product adjustment and could focus on smaller portion sizes, better labelling of food products and on changes in the composition of foods. During the Dutch EU chair ship in the first half of 2016, special attention will be devoted to product improvement.

Compared with other recent dietary guidelines, the Dutch guidelines are unique as they are exclusively formulated in terms of foods. In contrast, recent guidelines from USA, ${ }^{167}$ Australia ${ }^{168}$ and the Nordic countries ${ }^{169}$ combined the guidelines on foods with those on nutrients. For example, in the 2015-2020 Dietary Guidelines for Americans, vegetables, fruits, fat-free and low-fat dairy, a variety of protein foods and oils are promoted, whereas the recommendations are to limit the intake of saturated fats and trans fats, added sugars and sodium. ${ }^{167}$ Similarly, the Australian Dietary Guidelines encompass recommendations on specific foods that should be enjoyed every day and recommendations to limit the intake of foods containing saturated fat, added salt, added sugars and alcohol. ${ }^{168}$ The Nordic Nutrition Recommendations are phrased in terms of energy density, micronutrient density, carbohydrate quality and dietary fat quality and contain specific recommendations on limiting processed and red meat and the use of salt. They do also describe desired changes in terms of specific food groups that potentially promote energy balance and health in Nordic countries, which are largely in line with the Dutch guidelines. ${ }^{169}$

The Dutch dietary guidelines describe what is currently known about the constituents of a healthy dietary pattern in order to prevent chronic diseases. The Netherlands Nutrition Centre is currently translating these characteristics into public information on healthy eating. In this process, dietary reference values are also taken into account. The Netherlands Nutrition Centre's advice is expected to appear in spring 2016.

\section{CONFLICT OF INTEREST}

JB, JMG, JBVG, AWH, MTEH, JAI, RPM, HP, JAR, AMWJS, JCS, PV, MV and MHZ received compensation for meeting attendance and travelling expenses from the Health Council of the Netherlands; JB, AWH, JAI, DK, JAR, JCS and MV declare no other potential conflict of interest; JMG received research grants from the Dutch Dairy Association and Unilever; JBvG received research grants from Mead Johnson Nutrition, received research grants from, and was consultant for, Nutricia/Danone and received travel reimbursement and lecture fees from Nestle Nutrition Institute, all outside the submitted work; MTEH received a research grant from Unilever; RPM received research grants from Top Institute Food and Nutrition and Unilever; HP was consultant for L-Nutra and occiasionally scientific advisor for Tasty Basics, outside the submitted work; AMWJS was member of the scientific advisory board of Nutricia
Advanced Medical Nutrition, outside the submitted work; PvV received research grants from Top Institute Food and Nutrition, a public-private partnership; and MHZ received grants from research funding from a public-private partnership sponsorded by Danone, Unilever and Corbion, outside the submitted work, and was occasionally scientific advisor for Danone, Unilever, Corbion and Intersnack, outside the submitted work. JG, CJK and RMW declare no conflict of interest. Supplementary Appendix 1 contains a detailed explanation of how the Health Council has handled interests of the committee.

\section{ACKNOWLEDGEMENTS}

This work summarizes an advisory report by the Health Council of the Netherlands. The writing group was at the time employed at the Health Council of the Netherlands. The committee received compensation for meeting attendance and travelling expenses from the Health Council of the Netherlands.

\section{THE COMMITTEE DUTCH DIETARY GUIDELINES 2015}

Johannes Brug ${ }^{2}$, Johanna M Geleijnse ${ }^{3}$, Johannes B van Goudoever ${ }^{4}$, Arno W Hoes $^{5}$, Maria TE Hopman ${ }^{6}$, Jolein A lestra ${ }^{7}$, Ronald P Mensink ${ }^{8}$, Hanno Pijl ${ }^{9}$, Johannes A Romijn ${ }^{10}$, Annemie MWJ Schols ${ }^{11}$, Jaap C Seidell ${ }^{12}$, Pieter van 't Veer ${ }^{13}$, Marjolein Visser ${ }^{14}$, Marcel H Zwietering ${ }^{15}$

${ }^{2}$ Professor of Epidemiology, VU Medical Center, Amsterdam, The Netherlands; ${ }^{3}$ Professor of Nutrition and Cardiovascular Diseases, Wageningen University, Division of Human Nutrition, Wageningen, The Netherlands; ${ }^{4}$ Professor of Paediatrics, Department of Pediatrics, VU University Medical Center Amsterdam and Emma Children's Hospital-Academic Medical Center, Amsterdam, The Netherlands; ${ }^{5}$ Professor of Clinical Epidemiology and General Practice, Division Julius Centre, University Medical Center Utrecht, Utrecht, The Netherlands; ${ }^{6}$ Professor of Integrative Physiology, Department of Physiology, Radboud University Medical Center, Group Integrative Physiology, Nijmegen, The Netherlands; ${ }^{7}$ Nutritionist, Division Julius Centre, University Medical Center Utrecht, Utrecht, The Netherlands; ${ }^{8}$ Professor of Molecular Nutrition, Faculty of Health, Medicine and Life Sciences, Department of Human Biology, Maastricht University, Maastricht, The Netherlands; ${ }^{9}$ Professor of Diabetology, Department of Internal Medicine, Leiden University Medical Center, Leiden, The Netherlands; ${ }^{10}$ Professor of Internal Medicine, Department of Internal Medicine, Academic Medical Center, Amsterdam, The Netherlands; ${ }^{11}$ Professor of Nutrition and Metabolism in Chronic Diseases, Maastricht University Medical Centre, NUTRIM Research School, Maastricht, The Netherlands; ${ }^{12}$ Professor of Nutrition and Health, Department of Nutrition and Health, Faculty of Earth and Life Sciences, Instute for Health Sciences, VU University, De Boelelaan, Amsterdam, The Netherlands; ${ }^{13}$ Professor of Nutrition, Public Health and Sustainability, Division of Human Nutrition, Wageningen University, Wageningen, The Netherlands; ${ }^{14}$ Professor of Healthy Aging, Faculty of Earth and Life Sciences, Instute for Health Sciences, Department of Nutrition and Health \& VU University Medical Center, Department of Internal Medicine, Section Nutrition and Dietetics, VU University, Amsterdam, The Netherlands; ${ }^{15}$ Professor of Food Microbiology, Laboratory of Food Microbiology, Wageningen University, Wageningen, The Netherlands.

\section{REFERENCES}

1 Voedingsraad. Advies Richtlijnen goede voeding. Den Haag. 1986.

2 Health Council of the Netherlands. Guidelines for a Healthy Diet 2006. Publication no. 2006/21E. The Hague, 2006.

3 Mozaffarian D, Ludwig DS. Dietary guidelines in the 21 st century--a time for food. JAMA 2010; 304: 681-682.

4 Health Council of the Netherlands. Background Document Methodology for the Evaluation of the Evidence for the Dutch Dietary Guidelines 2015. Publication no. A15/03E. The Hague, 2015.

5 Grobbee DE, Hoes AW. Clinical Epidemiology Principles, Methods, and Applications for Clinical Research. Jones and Bartlett Publ, Inc., 2007.

6 Cooper AJ, Forouhi NG, Ye Z, Buijsse B, Arriola L, Balkau B et al. Fruit and vegetable intake and type 2 diabetes: EPIC-InterAct prospective study and meta-analysis. Eur J Clin Nutr 2012; 66: 1082-1092.

7 Broekmans WM, Klopping-Ketelaars WA, Kluft C, van den Berg H, Kok FJ, van Poppel G. Fruit and vegetables and cardiovascular risk profile: a diet controlled intervention study. Eur J Clin Nutr 2001; 55: 636-642. 
8 Berry SE, Mulla UZ, Chowienczyk PJ, Sanders TA. Increased potassium intake from fruit and vegetables or supplements does not lower blood pressure or improve vascular function in UK men and women with early hypertension: a randomised controlled trial. Br J Nutr 2010; 104: 1839-1847.

9 Appel LJ, Moore TJ, Obarzanek E, Vollmer WM, Svetkey LP, Sacks FM et al. A clinical trial of the effects of dietary patterns on blood pressure. DASH Collaborative Research Group. N Engl J Med 1997; 336: 1117-1124.

10 John JH, Ziebland S, Yudkin P, Roe LS, Neil HA. Effects of fruit and vegetable consumption on plasma antioxidant concentrations and blood pressure: a randomised controlled trial. Lancet 2002; 359: 1969-1974.

11 McCall DO, McGartland CP, McKinley MC, Patterson CC, Sharpe P, McCance DR et al. Dietary intake of fruits and vegetables improves microvascular function in hypertensive subjects in a dose-dependent manner. Circulation 2009; 119: 2153-2160.

12 Smith-Warner SA, Elmer PJ, Tharp TM, Fosdick L, Randall B, Gross M et al. Increasing vegetable and fruit intake: randomized intervention and monitoring in an at-risk population. Cancer Epidemiol Biomarkers Prev 2000; 9: 307-317.

13 He FJ, Nowson CA, Lucas M, Macgregor GA. Increased consumption of fruit and vegetables is related to a reduced risk of coronary heart disease: meta-analysis of cohort studies. J Hum Hypertens 2007; 21: 717-728.

14 Dauchet L, Amouyel P, Hercberg S, Dallongeville J. Fruit and vegetable consumption and risk of coronary heart disease: a meta-analysis of cohort studies. J Nutr 2006; 136: 2588-2593.

15 Crowe FL, Roddam AW, Key TJ, Appleby PN, Overvad K, Jakobsen MU et al. Fruit and vegetable intake and mortality from ischaemic heart disease: results from the European Prospective Investigation into Cancer and Nutrition (EPIC)Heart study. Eur Heart J 2011; 32: 1235-1243.

16 Hu D, Huang J, Wang Y, Zhang D, Qu Y. Fruits and vegetables consumption and risk of stroke: a meta-analysis of prospective cohort studies. Stroke 2014; 45: 1613-1619.

17 Brown L, Rosner B, Willett WW, Sacks FM. Cholesterol-lowering effects of dietary fiber: a meta-analysis. Am J Clin Nutr 1999; 69: 30-42.

18 Muraki I, Imamura F, Manson JE, Hu FB, Willett WC, van Dam RM et al. Fruit consumption and risk of type 2 diabetes: results from three prospective longitudinal cohort studies. BMJ 2013; 347: f5001.

19 Aune D, Lau R, Chan DS, Vieira R, Greenwood DC, Kampman E et al. Nonlinear reduction in risk for colorectal cancer by fruit and vegetable intake based on meta-analysis of prospective studies. Gastroenterology 2011; 141: 106-118.

20 World Cancer Research Fund/American Institute for Cancer Research. Food, Nutrition, Physical Activity, and the Prevention of Cancer: a Global Perspective. Washington, DC, 2007.

21 Buchner FL, Bueno-de-Mesquita HB, Linseisen J, Boshuizen HC, Kiemeney LA Ros $\mathrm{MM}$ et al. Fruits and vegetables consumption and the risk of histological subtypes of lung cancer in the European Prospective Investigation into Cancer and Nutrition (EPIC). Cancer Causes Control 2010; 21: 357-371.

22 Wakai K, Matsuo K, Nagata C, Mizoue T, Tanaka K, Tsuji I et al. Lung cancer risk and consumption of vegetables and fruit: an evaluation based on a systematic review of epidemiological evidence from Japan. Jpn J Clin Oncol 2011; 41: 693-708.

23 Rohrmann S, Overvad K, Bueno-de-Mesquita HB, Jakobsen MU, Egeberg R, Tjonneland $\mathrm{A}$ et al. Meat consumption and mortality - results from the European Prospective Investigation into Cancer and Nutrition. BMC Med 2013; 11: 63.

24 Kaluza J, Wolk A, Larsson SC. Red meat consumption and risk of stroke: a metaanalysis of prospective studies. Stroke 2012; 43: 2556-2560.

25 Chen GC, Lv DB, Pang Z, Liu QF. Red and processed meat consumption and risk of stroke: a meta-analysis of prospective cohort studies. Eur J Clin Nutr 2013; 67: 91-95.

26 Micha R, Wallace SK, Mozaffarian D. Red and processed meat consumption and risk of incident coronary heart disease, stroke, and diabetes mellitus: a systematic review and meta-analysis. Circulation 2010; 121: 2271-2283.

27 Aune D, Ursin G, Veierod MB. Meat consumption and the risk of type 2 diabetes: a systematic review and meta-analysis of cohort studies. Diabetologia 2009; 52 2277-2287.

28 Pan A, Sun Q, Bernstein AM, Schulze MB, Manson JE, Willett WC et al. Red meat consumption and risk of type 2 diabetes: 3 cohorts of US adults and an updated meta-analysis. Am J Clin Nutr 2011; 94: 1088-1096.

29 Feskens EJ, Sluik D, van Woudenbergh GJ. Meat consumption, diabetes, and its complications. Curr Diab Rep 2013; 13: 298-306.

30 Chan DS, Lau R, Aune D, Vieira R, Greenwood DC, Kampman E et al. Red and processed meat and colorectal cancer incidence: meta-analysis of prospective studies. PLoS One 2011; 6: e20456.

31 Norat T, Chan DS, Lau R, Aune D, Vieira R, WCRF/AIRC Systematic literature review continuous update project report. The associations between food, nutrition, physical activity and risk of colorectal cancer, 2010. Available from: http://www.wcrf.org/sites/default/files/SLR_colorectal_cancer_2010.pdf.

32 Huxley RR, Ansary-Moghaddam A, Clifton P, Czernichow S, Parr CL, Woodward M. The impact of dietary and lifestyle risk factors on risk of colorectal cancer: a quantitative overview of the epidemiological evidence. Int J Cancer 2009; 125: 171-180.

33 Alexander DD, Weed DL, Cushing CA, Lowe KA. Meta-analysis of prospective studies of red meat consumption and colorectal cancer. Eur J Cancer Prev 2011; 20: 293-307.

34 Alexander DD, Miller AJ, Cushing CA, Lowe KA. Processed meat and colorectal cancer: a quantitative review of prospective epidemiologic studies. Eur J Cancer Prev 2010; 19: 328-341.

35 Spencer EA, Key TJ, Appleby PN, Dahm CC, Keogh RH, Fentiman IS et al. Meat, poultry and fish and risk of colorectal cancer: pooled analysis of data from the UK dietary cohort consortium. Cancer Causes Control 2010; 21: 1417-1425.

36 Yang WS, Wong MY, Vogtmann E, Tang RQ, Xie L, Yang YS et al. Meat consumption and risk of lung cancer: evidence from observational studies. Ann Oncol 2012; 23: 3163-3170

37 Xue XJ, Gao Q, Qiao JH, Zhang J, Xu CP, Liu J. Red and processed meat consumption and the risk of lung cancer: a dose-response meta-analysis of 33 published studies. Int J Clin Exp Med 2014; 7: 1542-1553.

38 Abete I, Romaguera D, Vieira AR, Lopez de MA, Norat T. Association between total, processed, red and white meat consumption and all-cause, CVD and IHD mortality: a meta-analysis of cohort studies. Br J Nutr 2014; 112: 762-775.

39 Missmer SA, Smith-Warner SA, Spiegelman D, Yaun SS, Adami HO, Beeson WL et al. Meat and dairy food consumption and breast cancer: a pooled analysis of cohort studies. Int J Epidemiol 2002; 31: 78-85.

40 Aune D, Lau R, Chan DS, Vieira R, Greenwood DC, Kampman E et al. Dairy products and colorectal cancer risk: a systematic review and meta-analysis of cohort studies. Ann Oncol 2012; 23: 37-45.

41 Ralston RA, Truby H, Palermo CE, Walker KZ. Colorectal cancer and nonfermented milk, solid cheese, and fermented milk consumption: a systematic review and meta-analysis of prospective studies. Crit Rev Food Sci Nutr 2014; 54: 1167-1179.

42 Chen M, Sun Q, Giovannucci E, Mozaffarian D, Manson JE, Willett WC et al. Dairy consumption and risk of type 2 diabetes: 3 cohorts of US adults and an updated meta-analysis. BMC Med 2014; 12: 215.

43 Keum N, Aune D, Greenwood DC, Ju W, Giovannucci EL. Calcium intake and colorectal cancer risk: dose-response meta-analysis of prospective observational studies. Int J Cancer 2014; 135: 1940-1948.

44 Huncharek M, Muscat J, Kupelnick B. Colorectal cancer risk and dietary intake of calcium, vitamin D, and dairy products: a meta-analysis of 26,335 cases from 60 observational studies. Nutr Cancer 2009; 61: 47-69.

45 Rossum CTM, van, Fransen HP, Verkaik-Kloosterman J, Buurma-Rethans EJM, Ocké MC. Dutch National Food Consumption Survey 2007-2010. Diet of children and adults aged 7 to 69 years. Report no.: 350050006/2011. Bilthoven, 2011.

46 Weggemans RM, Zock PL, Katan MB. Dietary cholesterol from eggs increases the ratio of total cholesterol to high-density lipoprotein cholesterol in humans: a meta-analysis. Am J Clin Nutr 2001; 73: 885-891.

47 Berger S, Raman G, Vishwanathan R, Jacques PF, Johnson EJ. Dietary cholesterol and cardiovascular disease: a systematic review and meta-analysis. Am J Clin Nutr 2015; 102: 276-294.

48 Rong Y, Chen L, Zhu T, Song Y, Yu M, Shan Z et al. Egg consumption and risk of coronary heart disease and stroke: dose-response meta-analysis of prospective cohort studies. BMJ 2013; 346: e8539.

49 Shin JY, Xun $P$, Nakamura $Y$, He K. Egg consumption in relation to risk of cardiovascular disease and diabetes: a systematic review and meta-analysis. Am J Clin Nutr 2013; 98: 146-159.

50 Bazzano LA, Thompson AM, Tees MT, Nguyen CH, Winham DM. Non-soy legume consumption lowers cholesterol levels: a meta-analysis of randomized controlled trials. Nutr Metab Cardiovasc Dis 2011; 21: 94-103.

$51 \mathrm{Ha} \mathrm{V}$, Sievenpiper JL, de Souza RJ, Jayalath VH, Mirrahimi A, Agarwal A et al. Effect of dietary pulse intake on established therapeutic lipid targets for cardiovascular risk reduction: a systematic review and meta-analysis of randomized controlled trials. CMAJ 2014; 186: E252-E262.

52 Afshin A, Micha R, Khatibzadeh S, Mozaffarian D. Consumption of nuts and legumes and risk of incident ischemic heart disease, stroke, and diabetes: a systematic review and meta-analysis. Am J Clin Nutr 2014; 100: 278-288.

53 Banel DK, Hu FB. Effects of walnut consumption on blood lipids and other cardiovascular risk factors: a meta-analysis and systematic review. Am J Clin Nutr 2009; 90: 56-63.

54 Pan A, Yu D, mark-Wahnefried W, Franco OH, Lin X. Meta-analysis of the effects of flaxseed interventions on blood lipids. Am J Clin Nutr 2009; 90: 288-297.

55 Sabate J, Oda K, Ros E. Nut consumption and blood lipid levels: a pooled analysis of 25 intervention trials. Arch Intern Med 2010; 170: 821-827. 
56 Luo C, Zhang Y, Ding Y, Shan Z, Chen S, Yu M et al. Nut consumption and risk of type 2 diabetes, cardiovascular disease, and all-cause mortality: a systematic review and meta-analysis. Am J Clin Nutr 2014; 100: 256-269.

57 Estruch R, Ros E, Salas-Salvado J, Covas MI, Corella D, Aros F et al. Primary prevention of cardiovascular disease with a Mediterranean diet. $N$ Engl J Med 2013; 368: 1279-1290.

58 Cho SS, Qi L, Fahey GC Jr, Klurfeld DM. Consumption of cereal fiber, mixtures of whole grains and bran, and whole grains and risk reduction in type 2 diabetes, obesity, and cardiovascular disease. Am J Clin Nutr 2013; 98: 594-619.

59 Djousse L, Gaziano JM. Breakfast cereals and risk of heart failure in the physicians' health study I. Arch Intern Med 2007; 167: 2080-2085.

60 Jacobs DR Jr, Meyer KA, Kushi LH, Folsom AR. Is whole grain intake associated with reduced total and cause-specific death rates in older women? The lowa Women's Health Study. Am J Public Health 1999; 89: 322-329.

61 Nettleton JA, Steffen LM, Loehr LR, Rosamond WD, Folsom AR. Incident heart failure is associated with lower whole-grain intake and greater high-fat dairy and egg intake in the Atherosclerosis Risk in Communities (ARIC) study. J Am Diet Assoc 2008; 108: 1881-1887.

62 Streppel MT, Arends LR, van t V, Grobbee DE, Geleijnse JM. Dietary fiber and blood pressure: a meta-analysis of randomized placebo-controlled trials. Arch Intern Med 2005; 165: 150-156.

63 Whelton SP, Hyre AD, Pedersen B, Yi Y, Whelton PK, He J. Effect of dietary fiber intake on blood pressure: a meta-analysis of randomized, controlled clinical trials. J Hypertens 2005; 23: 475-481.

64 Threapleton DE, Greenwood DC, Evans CE, Cleghorn CL, Nykjaer C, Woodhead C et al. Dietary fibre intake and risk of cardiovascular disease: systematic review and meta-analysis. BMJ 2013; 347: f6879.

65 Zhang Z, Xu G, Liu D, Zhu W, Fan X, Liu X. Dietary fiber consumption and risk of stroke. Eur J Epidemiol 2013; 28: 119-130.

66 Bazzano LA, He J, Ogden LG, Loria CM, Whelton PK. Dietary fiber intake and reduced risk of coronary heart disease in US men and women: the National Health and Nutrition Examination Survey I Epidemiologic Follow-up Study. Arch Intern Med 2003; 163: 1897-1904.

67 Kelly SA, Summerbell CD, Brynes A, Whittaker V, Frost G. Wholegrain cereals for coronary heart disease. Cochrane Database Syst Rev 2007; (2): Art. no. CD005051.

68 AbuMweis SS, Jew S, Ames NP. beta-glucan from barley and its lipid-lowering capacity: a meta-analysis of randomized, controlled trials. Eur J Clin Nutr 2010; 64: 1472-1480.

69 EFSA Panel on Dietetic Products, Nutrition and Allergies (NDA). Scientific opinion on the substantiation of a health claim related to oat beta-glucans and lowering of blood cholesterol and reduced risk of (coronary) heart disease pursuant to Article 14 of Regulation (EC) No 1924/2006. EFSA J 2010; 8: 1885.

70 Talati R, Baker WL, Pabilonia MS, White CM, Coleman CI. The effects of barleyderived soluble fiber on serum lipids. Ann Fam Med 2009; 7: 157-163.

71 Anderson JW, Hanna TJ, Peng X, Kryscio RJ. Whole grain foods and heart disease risk. J Am Coll Nutr 2000; 19: 291S-299S.

72 Jensen MK, Koh-Banerjee P, Hu FB, Franz M, Sampson L, Gronbaek M et al. Intakes of whole grains, bran, and germ and the risk of coronary heart disease in men. Am J Clin Nutr 2004; 80: 1492-1499.

73 Liu S, Sesso HD, Manson JE, Willett WC, Buring JE. Is intake of breakfast cereals related to total and cause-specific mortality in men? Am J Clin Nutr 2003; 77: 594-599.

74 Steffen LM, Jacobs DR Jr, Stevens J, Shahar E, Carithers T, Folsom AR. Associations of whole-grain, refined-grain, and fruit and vegetable consumption with risks of all-cause mortality and incident coronary artery disease and ischemic stroke: the Atherosclerosis Risk in Communities (ARIC) Study. Am J Clin Nutr 2003; 78: 383-390.

75 Ye EQ, Chacko SA, Chou EL, Kugizaki M, Liu S. Greater whole-grain intake is associated with lower risk of type 2 diabetes, cardiovascular disease, and weight gain. J Nutr 2012; 142: 1304-1313.

76 Yao B, Fang H, Xu W, Yan Y, Xu H, Liu Y et al. Dietary fiber intake and risk of type 2 diabetes: a dose-response analysis of prospective studies. Eur J Epidemiol 2014; 29: 79-88.

77 Aune D, Norat T, Romundstad P, Vatten LJ. Whole grain and refined grain consumption and the risk of type 2 diabetes: a systematic review and doseresponse meta-analysis of cohort studies. Eur J Epidemiol 2013; 28: 845-858.

78 Aune D, Chan DS, Lau R, Vieira R, Greenwood DC, Kampman E et al. Dietary fibre, whole grains, and risk of colorectal cancer: systematic review and dose-response meta-analysis of prospective studies. BMJ 2011; 343: d6617.

79 Kyro C, Skeie G, Loft S, Landberg R, Christensen J, Lund E et al. Intake of whole grains from different cereal and food sources and incidence of colorectal cancer in the Scandinavian HELGA cohort. Cancer Causes Control 2013; 24: 1363-1374.
80 Hansen L, Skeie G, Landberg R, Lund E, Palmqvist R, Johansson I et al. Intake of dietary fiber, especially from cereal foods, is associated with lower incidence of colon cancer in the HELGA cohort. Int J Cancer 2012; 131: 469-478.

81 Murphy N, Norat T, Ferrari P, Jenab M, Bueno-de-Mesquita B, Skeie G et al. Dietary fibre intake and risks of cancers of the colon and rectum in the European prospective investigation into cancer and nutrition (EPIC). PLoS One 2012; 7: e39361.

82 Zock PL, Katan MB. Butter, margarine and serum lipoproteins. Atherosclerosis 1997; 131: 7-16.

83 Mensink RP, Zock PL, Kester AD, Katan MB. Effects of dietary fatty acids and carbohydrates on the ratio of serum total to $\mathrm{HDL}$ cholesterol and on serum lipids and apolipoproteins: a meta-analysis of 60 controlled trials. Am J Clin Nutr 2003; 77: $1146-1155$.

84 Skeaff CM, Miller J. Dietary fat and coronary heart disease: summary of evidence from prospective cohort and randomised controlled trials. Ann Nutr Metab 2009; 55: 173-201.

85 Mozaffarian D, Micha R, Wallace S. Effects on coronary heart disease of increasing polyunsaturated fat in place of saturated fat: a systematic review and meta-analysis of randomized controlled trials. PLoS Med 2010; 7: e1000252.

86 Hooper L, Summerbell CD, Thompson R, Sills D, Roberts FG, Moore H et al. Reduced or modified dietary fat for preventing cardiovascular disease. Cochrane Database Syst Rev 2012; (5): Art. no. CD002137.

87 Ramsden CE, Zamora D, Leelarthaepin B, Majchrzak-Hong SF, Faurot KR, Suchindran CM et al. Use of dietary linoleic acid for secondary prevention of coronary heart disease and death: evaluation of recovered data from the Sydney Diet Heart Study and updated meta-analysis. BMJ 2013; 346: e8707.

88 Chowdhury R, Warnakula S, Kunutsor S, Crowe F, Ward HA, Johnson L et al. Association of dietary, circulating, and supplement fatty acids with coronary risk: a systematic review and meta-analysis. Ann Intern Med 2014; 160: 398-406.

89 Farvid MS, Cho E, Chen WY, Eliassen AH, Willett WC. Dietary protein sources in early adulthood and breast cancer incidence: prospective cohort study. BMJ 2014; 348: g3437.

90 Mozaffarian D, Aro A, Willett WC. Health effects of trans-fatty acids: experimental and observational evidence. Eur J Clin Nutr 2009; 63(Suppl 2): S5-S21.

91 Bendsen NT, Christensen R, Bartels EM, Astrup A. Consumption of industrial and ruminant trans fatty acids and risk of coronary heart disease: a systematic review and meta-analysis of cohort studies. Eur J Clin Nutr 2011; 65: 773-783.

92 Leon H, Shibata MC, Sivakumaran S, Dorgan M, Chatterley T, Tsuyuki RT. Effect of fish oil on arrhythmias and mortality: systematic review. BMJ 2008; 337: a2931.

93 Delgado-Lista J, Perez-Martinez P, Lopez-Miranda J, Perez-Jimenez F. Long chain omega-3 fatty acids and cardiovascular disease: a systematic review. Br J Nutr 2012; 107(Suppl 2): S201-S213.

94 Trikalinos TA, Moorthy D, Yu WW, Lau J, Lichtenstein AH, Chung M. Nutritional Research Series. Volume 4: Effects of Eicosapentanoic Acid and Docosahexanoic Acid on Mortality across Diverse Settings: Systematic Review and Meta-analysis of Randomized Trials and Prospective Cohorts. Agency for Health Care Research and Quality: Rockville, MD, USA, 2012.

95 Kwak SM, Myung SK, Lee YJ, Seo HG. Efficacy of omega-3 fatty acid supplements (eicosapentaenoic acid and docosahexaenoic acid) in the secondary prevention of cardiovascular disease: a meta-analysis of randomized, double-blind, placebocontrolled trials. Arch Intern Med 2012; 172: 686-694.

96 Rizos EC, Ntzani EE, Bika E, Kostapanos MS, Elisaf MS. Association between omega-3 fatty acid supplementation and risk of major cardiovascular disease events: a systematic review and meta-analysis. JAMA 2012; 308: 1024-1033.

97 Wen YT, Dai JH, Gao Q. Effects of Omega-3 fatty acid on major cardiovascular events and mortality in patients with coronary heart disease: a metaanalysis of randomized controlled trials. Nutr Metab Cardiovasc Dis 2014; 24: 470-475.

98 Zheng J, Huang T, Yu Y, Hu X, Yang B, Li D. Fish consumption and CHD mortality: an updated meta-analysis of seventeen cohort studies. Public Health Nutr 2012; 15: 725-737.

99 Engeset D, Braaten T, Teucher B, Kuhn T, Bueno-de-Mesquita HB, Leenders M et al. Fish consumption and mortality in the European Prospective Investigation into Cancer and Nutrition cohort. Eur J Epidemiol 2015; 30: 57-70.

100 Burr ML, Fehily AM, Gilbert JF, Rogers S, Holliday RM, Sweetnam PM et al. Effects of changes in fat, fish, and fibre intakes on death and myocardial reinfarction: diet and reinfarction trial (DART). Lancet 1989; 2: 757-761.

101 Larsson SC, Orsini N. Fish consumption and the risk of stroke: a dose-response meta-analysis. Stroke 2011; 42: 3621-3623.

102 Xun P, Qin B, Song Y, Nakamura Y, Kurth T, Yaemsiri S et al. Fish consumption and risk of stroke and its subtypes: accumulative evidence from a meta-analysis of prospective cohort studies. Eur J Clin Nutr 2012; 66: 1199-1207. 
103 Chowdhury R, Stevens S, Gorman D, Pan A, Warnakula S, Chowdhury S et al. Association between fish consumption, long chain omega 3 fatty acids, and risk of cerebrovascular disease: systematic review and meta-analysis. BMJ 2012; 345: e6698.

104 EFSA Scientific Committee. Statement on the benefits of fish/seafood consumption compared to the risks of methylmercury in fish/seafood. EFSA J 2015; 13: 3982.

105 Khalesi S, Sun J, Buys N, Jamshidi A, Nikbakht-Nasrabadi E, Khosravi-Boroujeni H. Green tea catechins and blood pressure: a systematic review and meta-analysis of randomised controlled trials. Eur J Nutr 2014; 53: 1299-1311.

106 Onakpoya I, Spencer E, Heneghan C, Thompson M. The effect of green tea on blood pressure and lipid profile: a systematic review and meta-analysis of randomized clinical trials. Nutr Metab Cardiovasc Dis 2014; 24: 823-836.

107 Greyling A, Ras RT, Zock PL, Lorenz M, Hopman MT, Thijssen DH et al. The effect of black tea on blood pressure: a systematic review with meta-analysis of randomized controlled trials. PLoS One 2014; 9: e103247.

108 Shen L, Song LG, Ma H, Jin CN, Wang JA, Xiang MX. Tea consumption and risk of stroke: a dose-response meta-analysis of prospective studies. J Zhejiang Univ Sci B 2012; 13: 652-662.

109 Yang WS, Wang WY, Fan WY, Deng Q, Wang X. Tea consumption and risk of type 2 diabetes: a dose-response meta-analysis of cohort studies. Br J Nutr 2014; 111 1329-1339.

110 Urgert R, Katan MB. The cholesterol-raising factor from coffee beans. J R Soc Med 1996; 89: 618-623.

111 Voorlichtingsbureau voor Koffie en Gezondheid. Koffie, hart en bloedvaten, Amsterdam, 2007.

112 Cai L, Ma D, Zhang Y, Liu Z, Wang P. The effect of coffee consumption on serum lipids: a meta-analysis of randomized controlled trials. Eur J Clin Nutr 2012; 66 872-877

113 Ding M, Bhupathiraju SN, Satija A, van Dam RM, Hu FB. Long-term coffee consumption and risk of cardiovascular disease: a systematic review and a doseresponse meta-analysis of prospective cohort studies. Circulation 2014; 129 . 643-659.

114 Malik VS, Pan A, Willett WC, Hu FB. Sugar-sweetened beverages and weight gain in children and adults: a systematic review and meta-analysis. Am J Clin Nutr 2013; 98: 1084-1102

115 Greenwood DC, Threapleton DE, Evans CE, Cleghorn CL, Nykjaer C, Woodhead C et al. Association between sugar-sweetened and artificially sweetened soft drinks and type 2 diabetes: systematic review and dose-response meta-analysis of prospective studies. Br J Nutr 2014; 112: 725-734.

116 Xi B, Li S, Liu Z, Tian H, Yin X, Huai P et al. Intake of fruit juice and incidence of type 2 diabetes: a systematic review and meta-analysis. PLoS One 2014; 9: e93471.

117 Xin X, He J, Frontini MG, Ogden LG, Motsamai OI, Whelton PK. Effects of alcohol reduction on blood pressure: a meta-analysis of randomized controlled trials. Hypertension 2001; 38: 1112-1117.

118 Ronksley PE, Brien SE, Turner BJ, Mukamal KJ, Ghali WA. Association of alcohol consumption with selected cardiovascular disease outcomes: a systematic review and meta-analysis. BMJ 2011; 342: d671.

119 Roerecke M, Rehm J. Irregular heavy drinking occasions and risk of ischemic heart disease: a systematic review and meta-analysis. Am J Epidemiol 2010; 171: 633-644

120 Hamajima N, Hirose K, Tajima K, Rohan T, Calle EE, Heath CW Jr et al. Alcohol, tobacco and breast cancer--collaborative reanalysis of individual data from 53 epidemiological studies, including 58,515 women with breast cancer and 95,067 women without the disease. Br J Cancer 2002; 87: 1234-1245.

121 Romieu I, Scoccianti C, Chajes V, de BJ, Biessy C, Dossus L et al. Alcohol intake and breast cancer in the European prospective investigation into cancer and nutrition. Int J Cancer 2015; 137: 1921-1930.

122 Seitz HK, Pelucchi C, Bagnardi V, La VC. Epidemiology and pathophysiology of alcohol and breast cancer: Update 2012. Alcohol Alcohol 2012; 47: 204-212.

123 Cho E, Smith-Warner SA, Ritz J, van den Brandt PA, Colditz GA, Folsom AR et al. Alcohol intake and colorectal cancer: a pooled analysis of 8 cohort studies. Ann Intern Med 2004; 140: 603-613.

124 Ferrari $\mathrm{P}$, Jenab M, Norat T, Moskal A, Slimani N, Olsen A et al. Lifetime and baseline alcohol intake and risk of colon and rectal cancers in the European prospective investigation into cancer and nutrition (EPIC). Int J Cancer 2007; 121 2065-2072.

125 Moskal A, Norat T, Ferrari P, Riboli E. Alcohol intake and colorectal cancer risk: a dose-response meta-analysis of published cohort studies. Int J Cancer 2007; 120: 664-671

126 Chao C. Associations between beer, wine, and liquor consumption and lung cancer risk: a meta-analysis. Cancer Epidemiol Biomarkers Prev 2007; 16: 2436-2447.
127 Freudenheim JL, Ritz J, Smith-Warner SA, Albanes D, Bandera EV, van den Brandt PA et al. Alcohol consumption and risk of lung cancer: a pooled analysis of cohort studies. Am J Clin Nutr 2005; 82: 657-667.

128 Padilla H, Michael GJ, Djousse L. Alcohol consumption and risk of heart failure: a meta-analysis. Phys Sportsmed 2010; 38: 84-89.

129 Baliunas DO, Taylor BJ, Irving H, Roerecke M, Patra J, Mohapatra S et al. Alcohol as a risk factor for type 2 diabetes: a systematic review and meta-analysis. Diabetes Care 2009; 32: 2123-2132.

130 Beulens JW, van der Schouw YT, Bergmann MM, Rohrmann S, Schulze MB, Buijsse $B$ et al. Alcohol consumption and risk of type 2 diabetes in European men and women: influence of beverage type and body size The EPIC-InterAct study. J Intern Med 2012; 272: 358-370.

131 Koppes LL, Dekker JM, Hendriks HF, Bouter LM, Heine RJ. Moderate alcohol consumption lowers the risk of type 2 diabetes: a meta-analysis of prospective observational studies. Diabetes Care 2005; 28: 719-725.

132 Anstey KJ, Mack HA, Cherbuin N. Alcohol consumption as a risk factor for dementia and cognitive decline: meta-analysis of prospective studies. Am J Geriatr Psychiatry 2009; 17: 542-555.

133 Ferrari $\mathrm{P}$, Licaj I, Muller DC, Kragh AP, Johansson $\mathrm{M}$, Boeing $\mathrm{H}$ et al. Lifetime alcohol use and overall and cause-specific mortality in the European Prospective Investigation into Cancer and nutrition (EPIC) study. BMJ Open 2014; 4: e005245.

134 DiCastelnuovo A, Costanzo S, Bagnardi V, Donati MB, lacoviello L, de Gaetano G. Alcohol dosing and total mortality in men and women: an updated metaanalysis of 34 prospective studies. Arch Intern Med 2006; 166: 2437-2445.

135 Aburto NJ, Ziolkovska A, Hooper L, Elliott P, Cappuccio FP, Meerpohl JJ. Effect of lower sodium intake on health: systematic review and meta-analyses. BMJ 2013; 346: f1326.

136 Graudal NA, Hubeck-Graudal T, Jurgens G. Effects of low-sodium diet vs. highsodium diet on blood pressure, renin, aldosterone, catecholamines, cholesterol, and triglyceride. Cochrane Database Syst Rev 2011; (11): Art. no. CD004022.

137 He FJ, Li J, Macgregor GA. Effect of longer term modest salt reduction on blood pressure: Cochrane systematic review and meta-analysis of randomised trials. BMJ 2013; 346: 1-15.

138 Fortmann SP, Burda BU, Senger CA, Lin JS, Whitlock EP. Vitamin and mineral supplements in the primary prevention of cardiovascular disease and cancer: an updated systematic evidence review for the US Preventive Services Task Force. Ann Intern Med 2013; 159: 824-834.

139 The Alpha-Tocopherol Beta-Carotene Cancer Prevention Study Group. The effect of vitamin $E$ and beta carotene on the incidence of lung cancer and other cancers in male smokers. N Engl J Med 1994; 330: 1029-1035.

140 Omenn GS, Goodman GE, Thornquist MD, Balmes J, Cullen MR, Glass A et al. Effects of a combination of beta carotene and vitamin $A$ on lung cancer and cardiovascular disease. N Engl J Med 1996; 334: 1150-1155.

141 Bolland MJ, Grey A, Gamble GD, Reid IR. The effect of vitamin D supplementation on skeletal, vascular, or cancer outcomes: a trial sequential meta-analysis. Lancet Diabetes Endocrinol 2014; 2: 307-320.

142 Juraschek SP, Guallar E, Appel LJ, Miller ER III. Effects of vitamin C supplementation on blood pressure: a meta-analysis of randomized controlled trials. Am J Clin Nutr 2012; 95: 1079-1088.

143 Sesso HD, Buring JE, Christen WG, Kurth T, Belanger C, MacFadyen J et al. Vitamins $E$ and $C$ in the prevention of cardiovascular disease in men: the Physicians' Health Study II randomized controlled trial. JAMA 2008; 300: 2123-2133.

144 Nutrition Evidence Library. A Series of Systematic Reviews on the Relationship Between Dietary Patterns and Health Outcomes. US Department of Agriculture: Washington, DC, USA, 2014.

145 Saneei P, Salehi-Abargouei A, Esmaillzadeh A, Azadbakht L. Influence of Dietary Approaches to Stop Hypertension (DASH) diet on blood pressure: a systematic review and meta-analysis on randomized controlled trials. Nutr Metab Cardiovasc Dis 2014; 24: 1253-1261.

146 Brader L, Uusitupa M, Dragsted LO, Hermansen K. Effects of an isocaloric healthy Nordic diet on ambulatory blood pressure in metabolic syndrome: a randomized SYSDIET sub-study. Eur J Clin Nutr 2014; 68: 57-63.

147 Poulsen SK, Due A, Jordy AB, Kiens B, Stark KD, Stender S et al. Health effect of the New Nordic Diet in adults with increased waist circumference: a 6-mo randomized controlled trial. Am J Clin Nutr 2014; 99: 35-45.

148 Adamsson V, Reumark A, Fredriksson IB, Hammarstrom E, Vessby B, Johansson G et al. Effects of a healthy Nordic diet on cardiovascular risk factors in hypercholesterolaemic subjects: a randomized controlled trial (NORDIET). J Intern Med 2011; 269: 150-159.

149 Salehi-Abargouei A, Maghsoudi Z, Shirani F, Azadbakht L. Effects of Dietary Approaches to Stop Hypertension (DASH)-style diet on fatal or nonfatal cardiovascular diseases--incidence: a systematic review and meta-analysis on observational prospective studies. Nutrition 2013; 29: 611-618.

150 Kontogianni MD, Panagiotakos DB. Dietary patterns and stroke: a systematic review and re-meta-analysis. Maturitas 2014; 79: 41-47. 
151 Yokoyama Y, Nishimura K, Barnard ND, Takegami M, Watanabe M, Sekikawa A et al. Vegetarian diets and blood pressure: a meta-analysis. JAMA Intern Med 2014; 174: 577-587.

152 Huang T, Yang B, Zheng J, Li G, Wahlqvist ML, Li D. Cardiovascular disease mortality and cancer incidence in vegetarians: a meta-analysis and systematic review. Ann Nutr Metab 2012; 60: 233-240.

153 Key TJ, Fraser GE, Thorogood M, Appleby PN, Beral V, Reeves G et al. Mortality in vegetarians and nonvegetarians: detailed findings from a collaborative analysis of 5 prospective studies. Am J Clin Nutr 1999; 70: 516S-524S.

154 Esposito K, Chiodini P, Maiorino MI, Bellastella G, Panagiotakos D, Giugliano D. Which diet for prevention of type 2 diabetes? A meta-analysis of prospective studies. Endocrine 2014; 47: 107-116.

155 Romaguera D, Guevara M, Norat T, Langenberg C, Forouhi NG, Sharp S et al. Mediterranean diet and type 2 diabetes risk in the European Prospective Investigation into Cancer and Nutrition (EPIC) study: the InterAct project. Diabetes Care 2011; 34: 1913-1918.

156 InterAct Consortium. Adherence to predefined dietary patterns and incident type 2 diabetes in European populations: EPIC-InterAct Study. Diabetologia 2014; 57: 321-333.

157 Schwingshackl L, Hoffmann G. Adherence to Mediterranean diet and risk of cancer: a systematic review and meta-analysis of observational studies. Int J Cancer 2014; 135: 1884-1897.

158 Sofi F, Macchi C, Abbate R, Gensini GF, Casini A. Mediterranean diet and health status: an updated meta-analysis and a proposal for a literature-based adherence score. Public Health Nutr 2014; 17: 2769-2782.

159 Health Council of the Netherlands. Guideline for Dietary Fibre Intake. Publication no. 2006/E3. The Hague, 2006.

160 Health Council of the Netherlands. Guidelines for a Healthy Diet: the Ecological Perspective. Publication no. 2011/08E. The Hague, 2011.
161 Tilman D, Clark M. Global diets link environmental sustainability and human health. Nature 2014; 515: 518-522.

162 Auestad N, Fulgoni VL III. What current literature tells us about sustainable diets: emerging research linking dietary patterns, environmental sustainability, and economics. Adv Nutr 2015; 6: 19-36.

163 Alsaffar AA. Sustainable diets: the interaction between food industry, nutrition, health and the environment. Food Sci Technol Int 2016; 22: 102-111.

164 Temme EH, Toxopeus IB, Kramer GF, Brosens MC, Drijvers JM, Tyszler M et al. Greenhouse gas emission of diets in the Netherlands and associations with food, energy and macronutrient intakes. Public Health Nutr 2015; 18: 2433-2445.

165 The Netherlands Scientific Council for Government Policy. Towards a Food Policy. Synopsis of WRR-report no. 93. The Hague, 2015.

166 Health Council of the Netherlands. Healthy Nutrition: a Closer Look at Logos. Publication no. 2008/22E. The Hague, 2008.

167 U.S. Department of Health and Human Services and U.S. Department of Agriculture. 2015-2020 Dietary Guidelines for Americans. Washington DC 2015.

168 National Health and Medical Research Council. Australian Dietary Guidelines. Canberra, 2013.

169 Nordic Nutrition Recommendations 2012. Integrating Nutrition and Physical Activity. Copenhagen 2014.

(c) (1)

This work is licensed under a Creative Commons Attribution 4.0 International License. The images or other third party material in this article are included in the article's Creative Commons license, unless indicated otherwise in the credit line; if the material is not included under the Creative Commons license, users will need to obtain permission from the license holder to reproduce the material. To view a copy of this license, visit http://creativecommons.org/licenses/ by/4.0/

Supplementary Information accompanies this paper on European Journal of Clinical Nutrition website (http://www.nature.com/ejcn) 